\title{
Article \\ The Projection of Gamification and Serious Games in the Learning of Mathematics Multi-Case Study of Secondary Schools in Italy
}

\author{
Viviana Malvasi $^{1}\left(\mathbb{D}\right.$, Javier Gil-Quintana ${ }^{1}(\mathbb{D})$ and Enrico Bocciolesi ${ }^{2, *(D)}$ \\ 1 Department of Education, National University of Distance Education, 28020 Madrid, Spain; \\ vmalvasi1@alumno.uned.es (V.M.); jgilquintana@edu.uned.es (J.G.-Q.) \\ 2 Dipartimento di Studi Umanistici, Università Degli Studi di Urbino Carlo Bo, 61029 Urbino, Italy \\ * Correspondence: enrico.bocciolesi@uniurb.it
}

check for updates

Citation: Malvasi, V.; Gil-Quintana, J.; Bocciolesi, E. The Projection of Gamification and Serious Games in the Learning of Mathematics Multi-Case Study of Secondary

Schools in Italy. Mathematics 2022, 10, 336. https://doi.org/10.3390/ math10030336

Academic Editors: Jay Jahangiri and Michael Gregory Voskoglou

Received: 2 December 2021

Accepted: 19 January 2022

Published: 22 January 2022

Publisher's Note: MDPI stays neutral with regard to jurisdictional claims in published maps and institutional affiliations.

Copyright: (C) 2022 by the authors. Licensee MDPI, Basel, Switzerland. This article is an open access article distributed under the terms and conditions of the Creative Commons Attribution (CC BY) license (https:// creativecommons.org/licenses/by/ $4.0 /)$.

\begin{abstract}
Our research was born with the objective of evaluating the level of gamification of high schools in Italy, specifically for mathematics, and the use of the serious game of chess as a resource for learning this discipline. The methodology is a mixed design, based on the combination of quantitative and qualitative techniques. Regarding the quantitative design, the instrument used was a questionnaire filled out by 4845 adolescents living in Italy. The qualitative methodology has focused on the analysis of the discourse of 12 in-depth interviews with mathematics teachers from high schools. Among the main results, we found that teachers, although unconsciously, apply gamification in classrooms (without having had any training about it) and, despite recognizing the mathematical benefits of chess, they do not use this game as a serious game. Our study confirms that gamification deserves more because of the benefits it brings, especially for a subject that scares students and demands greater motivation.
\end{abstract}

Keywords: mathematics education; mathematics; learning processes; teaching methods; secondary schools

\section{Introduction}

In the field of education, we have found in recent years the projection of the term gamification and, as a consequence, the publication of various studies that highlight the advantages and benefits of this approach that is integrated into the learning processes [1-5] and the impact that it has on learning and on interactive relationships [6-8]. Gamifying means introducing elements into a learning approach to turn it into a ludic proposal [9-11], and this has always been central to active and contemporary pedagogical issues. Numerous educators have suggested methods based on the possibilities of learning through play. This is the case of Montessori [12], which was based on the expressive freedom of young child through the ludic experience. The characterization and the relevance of the game were developed until reaching an essential reference for collaborative and integrative learning [13], a pattern of educational co-participation. In this perspective, serious play arises as a method that teachers use to develop certain learning for the benefits it brings [14]. In the case of mathematics, we analyzed chess as a serious game because it has been claimed as an effective tool to enhance children's mathematical abilities, as the game-similarly to mathematical tasks-demands children to use heuristics to correctly interpret problem situations and select the appropriate course of actions [15]; this game develops the ability to plan and solve problems because it trains the mind to reason, reflect, plan a strategy, and analyze the different possibilities of action $([16,17])$. Even if there are few studies about the correlation between chess and math learning, one of them was a meta-analysis of this theme [18]; the aim of this paper was to quantitatively evaluate the available empirical evidence that skills acquired during chess instruction in schools positively transfer to 
mathematics, reading, and general cognitive skills. The results show a tendency for a stronger effect on mathematical than reading skill. However, this meta-analysis denounces the lack of an "ideal design" including pre- and post-test and, most importantly, both a do-nothing control group and an active control group. Some months later, it was achieved in the study by Trinchero and Sala [15], where 931 primary school pupils were recruited and assigned to either one of two treatment groups attending chess lessons or a control group, and all were tested on their mathematical problem-solving abilities. The two treatment groups differed with regard to the teaching method adopted: the trainers (chess instructors) of one group taught the pupils heuristics to solve chess problems, whereas the trainers (schoolteachers) of the other group did not teach any chess-specific problemsolving heuristics. The results showed that the chess instructor-taught group outperformed the other two groups in mathematical problem-solving ability; these results encourage the hypothesis that a specific type of chess training improves children's mathematical skills.

Afterward, another study [19] analyzed the effect of substituting a weekly mathematics lesson in primary school grades 1-3 with a lesson in mathematics based on chess instruction. They found positive effects, indicating that knowledge acquired through chess play can be transferred to the domain of mathematics. The results are encouraging and suggest that chess may be an important and effective tool for improving mathematical capacity in young students.

Iş1kgöz [20] analyzed, for 274 students at five secondary school levels (5th, 6th, 7th and 8th grades), the contribution of secondary level chess to the success of math lesson by comparing end-year math scores of the secondary school students playing and not playing chess. He found a significant difference in end-year math scores in favor of the chess-playing students. We aimed to achieve something similar (analyzing the contribution of the chess level to the success of a math lesson by comparing math scores of secondary school student with their chess levels), but in grades 9-13. Accordingly, upon finding a significant difference, this would be useful for future investigations built with a design including pre-test and post-test, as well as a control group and a treatment group.

Our research assesses the level of gamification of secondary schools, specifically for the subject of mathematics, and the use of the serious game of chess as a resource for learning this discipline. This study is motivated by the fact that, in Italy, gamification and the use of serious games have still not yet taken on the importance they deserve, offering students and teachers the possibility of thinking from problem-posing [21] toward a ludic learning. The interest in this study arises from investigating the adolescent-game relationship under different issues, in formal or informal contexts, used for educational or ludic purposes, whether they are digital or nondigital games. A recent study by López, Couso, and Simarro [22] affirmed that mathematics (and STEM education in general) is a precious resource for digital learning, which is essential for modern reality. For this reason, we analyze the game as a resource in learning processes, and we specifically investigate the area of mathematics as it is a subject where students generally find greater difficulty [23] and have little motivation to learn [24].

We want to make a final reflection on videogames and the importance of their relative virtual learning communities. Videogames often do not have a "good reputation", especially if we refer to abuse by adolescents, causing decreased visual acuity or refractive problems [25], or psychological problems, causing low quality of sleep and high levels of stress [26]. Despite these negative issues, they should not be demonized. The videogame also has advantages such as the possibility it offers for the construction of virtual communities [27] where adolescents experience real emotional interactions and experiences; it has been observed that, in these interactive environments, their social relationships are manifested and even improved because strategies are discussed, world E-sports tournaments are organized, etc. Thus, a real society is presented in videogames where hierarchies, roles, and rules are personalized, remembering that these actions do not cease to exist when they disconnect or turn off the device, but continue to project and disseminate through social networks in ways that are not always dysfunctional. 
Considering these reflections, the point of view of our mixed methodological research was twofold: the opinion of students and teachers in the area of mathematics in Italian secondary education centers, achieving a broader and more complete vision of the object of study. On one hand, it was necessary to ask the students their relationship with games, their chess ability level, their math performance, the use of their math teacher of rewards or incentives in the learning process, and their opinion about use of games in didactic learning; on the other, it was important for our study to know teachers' knowledge about gamification, whether they use this didactic strategy, what they think about it, and what they think about chess as a tool in the mathematics learning/teaching process. We conclude our study by stating that gamification and the use of serious games in didactic practices improve not only learning, but also all those behaviors for which it is considered necessary to intervene to improve coexistence in the classrooms.

\section{Materials and Methods}

The methodological proposal of this multi-case study [28] aims to explore more than one analysis unit to proportionate the basis for its generalization [29]. This option provides criteria of internal and external validity and reliability of the collected data. The combination of quantitative and qualitative techniques in this multi-case study is presented through a mixed exploratory-correlational design. The instrument used for data collection was a questionnaire, completed by 4845 adolescents who live in Italy, with a total of 75 from 80 provinces that were conformed to the State. The questionnaire was elaborated with questions with concrete answers, to which we also added open and multiple-choice questions. The qualitative methodology [30-33] focused on discourse analysis [34-36] of 12 in-depth interviews involving high-school math teachers who were selected as privileged observers.

In order to specify the purpose of the study, we asked Italian students the following questions: [RQ1] Do you use the Internet for educational purposes (to study and/or to do homework)? If so, how many hours a day? [RQ2] Do you play videogames? If so, how many hours a day? [RQ3] Do you think that any videogame can help to improve in the area of mathematics? [RQ4] Are you part of virtual learning communities for these videogames? [RQ5] Do you play a game related to mathematics in your free time? [RQ6] Do you play games serious (nondigital) (on the table, outdoors, etc.)? [RQ7] Do the teachers propose digital games in math classes? [RQ8] Do the teachers propose serious (nondigital) games? [RQ9] What games proposed by the teachers have helped you better understand mathematics? [RQ10] Do you know games that could be used in mathematics classes? [RQ11] Do the mathematics teachers use incentives/prizes/rewards for doing homework well? [RQ12] Do the math teachers use incentives/prizes/rewards for doing exercises/problems in class well? [RQ13] Do you know how to play chess? If so, what is your level? [RQ14] Do you know the benefits of chess for learning mathematics?

Regarding the actions related to the teaching staff, we asked the following questions: [RQ15] What do you understand by gamification? How do you rate it? [RQ16] Have you received training related to this method? [RQ17] Do you know or propose any game to your students to help or facilitate the learning of mathematics (digital or nondigital)? [RQ18] Do you use incentives/prizes/rewards for the work done by your students? [RQ19] Do you use any digital application to grant this type of prize or reward? [RQ20] Using the game in educational practices is valued as a way of accustoming students to always receive rewards for what they do and not to make an effort; what do you think about this? [RQ21] Do you think that chess could be a good resource for teaching mathematics?

The questions presented above yielded the following objectives that specify this research

- Objective 1: Diagnose the purpose of the time spent on the Internet by Italian adolescents from a ludic or educational approach;

- $\quad$ Objective 2: Analyze whether the use of the Internet for educational purposes (to study and/or to do homework) depends on the independent variables gender, age, type of school, grade, or academic performance; 
- Objective 3: Analyze whether using the Internet to play videogames depends on the independent variables gender, age, type of school, grade, or academic performance;

- Objective 4: Detect the mathematical games most used by Italian adolescents among digital and nondigital games;

- Objective 5: Detect Italian adolescents' thinking about games (digital and nondigital) as an aid to learning mathematics and if they use them in math learning;

- Objective 6: Diagnose the level of application of gamification in Italian high school;

- Objective 7: Detect the knowledge that Italian high-school students have about the game of chess and its benefits for learning mathematics;

- Objective 8: Diagnose the Italian teachers' thinking about the didactic application of chess as a serious game.

The formulation of these objectives is related to a study designed to approximate observable phenomena. The hypotheses that we present below were contrasted and formulated using a hypothetical deductive method, related to the objectives of the study.

Hypothesis 1 (H1). Italian adolescents spend more time on the Internet for educational than recreational purposes;

Hypothesis 2 (H2). The use of the Internet for educational purposes does not depend on the independent variables gender, age, type of school, grade, and academic performance;

Hypothesis 3 (H3). The use of the Internet for videogames depends on the independent variables gender, age, type of school, grade, and academic performance;

Hypothesis 4 (H4). The games most used by high-school students are nondigital games;

Hypothesis 5 (H5). Italian high-school students think that games are not helpful for learning mathematics;

Hypothesis 6 (H6). In Italian high schools, gamification is applied by teachers in the area of mathematics;

Hypothesis 7 (H7). High-school students know the benefits of the game of chess for learning mathematics;

Hypothesis 8 (H8). Teachers in the area of mathematics believe in the use of chess as a serious game useful in learning processes.

\subsection{Participants}

The people participating in the sample were 4845 adolescents residing in Italy with ages between 13 and 22, and an average of 16.43 years. Among the people surveyed, 52\% were female and $48 \%$ were male. A total of 75 out of 80 provinces of residence were reached, across all of Italy: north $(60 \%)$, center $(7 \%)$, and south and islands $(33 \%)$. The people surveyed lived in more than 800 different localities: $66.6 \%$ in rural areas and $33.4 \%$ in urban areas. The reduced sample of the downtown area was not intentional, but in response to a request for participation by leaders from all three areas of the country, although, for the most part, they preferred not to supply the questionnaire due to the overload of the students for the lockdown period caused by the COVID-19 pandemic. According to data from the Istituto Nazionale di Statistica, the youth population (between 11 and 15 years old) was 2,854,720 in 2019; hence, the sample selected for this study exceeds the number necessary to obtain a confidence level $\geq 99 \%$, with a margin of error of $\pm 2 \%$. Therefore, from the data collected (also taking into account the geographical distribution), it is possible to make descriptive inferences. 
A total of 12 teaching teams of scientific disciplines participated in the interviews, of which $17 \%$ were male and $83 \%$ were female, aged between 32 and 59 years, with a teaching experience between 2 and 33 years. At the educational level, the sample had enormous potential for our study; it is of vital importance that $42 \%$ of the people interviewed had a degree in mathematics, $25 \%$ in statistical sciences, $17 \%$ in physics, and $8 \%$ each in economics and computer engineering, thus responding to all areas of STEM. Geographically, 58\% of the interviewed people lived and worked in the north of Italy, $8 \%$ lived and worked in the center, and 34\% lived and worked in the south and islands.

\subsection{Instruments}

In the quantitative study, the design of a questionnaire including closed, open, and multiple-response questions was chosen. The independent variables were gender, age, macro-area, type of school, grade, and academic performance. As dependent variables, we considered the different perspectives that allowed us to answer the questions, objectives, and hypotheses raised in the study. To give greater scientific rigor to the research, the IBM SPSS v.25 software was used, and correlations were established between outstanding variables.

For the qualitative approach, the design of a semi-structured interview with privileged observers was chosen, collecting personal information such as gender, age, city of education, type of educational center, years of experience, and level of training. The didactic methods most used by these teachers and the main difficulties encountered in their application were also analyzed. Using the Google Forms tool, an informed consensus form was generated so that the people interviewed gave consent for recording and analysis. During the interview, participants were asked to respond freely, while avoiding interruptions, although it was sometimes decided to influence some elements to get the teaching teams to offer a clearer answer. In order to make quick and simple references to the interviews and to differentiate the contributions of each of the people interviewed, we opted for the following coding: "E-Tn": page". In this coding we refer to the interview $(\mathrm{E})$, the teacher $(\mathrm{T})$, the interview number to which reference is made (no.), and the page where the referred event can be found (page). Therefore, if during the analysis, we report information that appears on the first page of the interview with participant 1, this is coded as E-T1: 1.

\subsection{Data Collection and Analysis Procedure}

The quantitative methodology, corresponding to the questionnaires applied to secondarylevel Italian high-school students, and the qualitative methodology, through semi-structured interviews with high-school teachers, allow analysis from both perspectives that enrich the process. Therefore, mixed methodologies typical of the social sciences are applied by combining, in a single study, research techniques, methods, approaches, concepts, and quantitative or qualitative language [37]. This makes it possible to acquire a greater understanding of what we are studying, encompassing the strengths of both methodologies and analyzing different approaches, combining the data to obtain convergent results [38].

For the questionnaires, a form sent to Italian educational centers was created, requesting their collaboration for this research. Once the necessary data were obtained, they were analyzed following the corresponding procedure. First, for the quantitative analysis, the csv data were exported to an Excel file for later interpretation with the statistical program IBM SPSS v. 25. We entered the data into the program by assigning numerical values to the responses obtained in the questionnaires, before proceeding to filtering, selecting the appropriate procedure to calculate the statistics, and executing the procedure in order to obtain the research reports. The interviews were all carried out by Skype and, subsequently, the transcription, compilation, and analysis of data related to the objectives and hypotheses were conducted. Lastly, a methodological triangulation was established, in addition to a comparison of the survey data with the results of the discourse analysis that we present in this study, respecting all the participants. 


\subsection{Ethical Consideration}

The sample interventions using the qualitative and quantitative techniques are distributed as follows: 12 people in the in-depth interviews and 4845 adolescents, both from Italian high schools. The completion of the questionnaires, like the speech of the interviews, was transcribed verbatim for categorization, while respecting anonymity. All subjects surveyed and interviewed were informed of the objectives of the study, the institutions that endorse it, and its voluntary nature. This was advocated, not only for anonymity, but also for the confidentiality of the data.

\subsection{Reliability and Validity}

This criterion determines whether the measurement scales of our tool are reliable, understanding reliability as the precision of the instrument, taking into account the possible errors found in the factor analysis. If the errors that are presented are smaller, the precision of the measurement and, therefore, of the study is considered greater. To study the reliability of the instrument, we followed the Cronbach $\alpha$ procedure. After analyzing the reliability statistics, it can be said that Cronbach's $\alpha$ offered a value of 0.66 . Regarding content validity, the opinion and the validation of 10 researchers from the SMEMIU group of the National University of Distance Education (Spain) were taken into account in the design of the research instruments. It was concluded that the relevance of the items is high since the objectives of the study are related to the approach of the instruments; an absence of differences was observed in the evaluations of the set of sections of the questionnaire and the interview script, as well as the content validity criteria.

\section{Results}

The data collected from both the questionnaires and the interviews were organized into the following categories: 1 . Online adolescents: recreational purposes or educational purposes? 2. Digital games or nondigital games? Do games help in learning mathematics? 3. Level of application of gamification. 4. Chess and learning mathematics.

\subsection{Category 1. Online Adolescents: Recreational Purposes or Educational Purposes?}

Referring to the use that students make of the Internet, we can see in Table 1, which details the multiple-choice answers, that to RQ1 ("Do you use the Internet for educational purposes?"), $99.7 \%$ of the students answered positively, stating that they used email (82\%), Word/Excel/PowerPoint (81.9\%), chat (81.7\%), information search tools such as Google or Yahoo (79.7\%), videoconferences $(74.3 \%)$, and audiovisual content platforms $(61 \%)$.

Advancing in the use of Internet with a ludic purpose, in terms of RQ3 ("Do you play videogames?"), $43.1 \%$ of the students answered positively. The games that had the most impact were FIFA or PES2020, Fortnite, and Call of Duty. Referring to RQ4 ("Are you part of virtual communities of these videogames?"), $88 \%$ answered negatively. We highlighted an association between the hours a day spent on the Internet for educational purposes and the hours spent playing videogames, showing a contingency coefficient of 0.241 and significance $<0.05$. The answers had the same percentage for the answer " $1-2 \mathrm{~h}$ ", decreasing together, although the time spent on the Internet for educational purposes was more than to play, as seen in Figure 1.

We can observe in the study that between playing videogames in free time and male gender, there was a moderate correlation (correlation coefficient 0.313 ) with the games FIFA or PES2020, as well as with Fortnite (0.216), Call of Duty (0.224), and unspecified (0.212). These data are corroborated by the strong correlation (0.539) between the number of hours of use per day and gender, with a significance $<0.05$, as can be seen in Table 2 . 
Table 1. The use that students make of the Internet.

\begin{tabular}{cc}
\hline Emails & $82.00 \%$ \\
\hline Word, Excel, PowerPoint & $81.90 \%$ \\
\hline Chat & $81.70 \%$ \\
\hline $\begin{array}{c}\text { Information search tools } \\
\text { (Google, Yhaoo, DB) }\end{array}$ & $79.70 \%$ \\
\hline Videoconferences & $74.30 \%$ \\
\hline Audiovisual content platforms & $61.00 \%$ \\
\hline Digital files & $33.50 \%$ \\
\hline Forum & $17.60 \%$ \\
\hline Screenshot tools & $11.80 \%$ \\
\hline Online collaborative tools (Blogs, Wikis) & $11.50 \%$ \\
\hline Apps & $0.40 \%$ \\
\hline
\end{tabular}

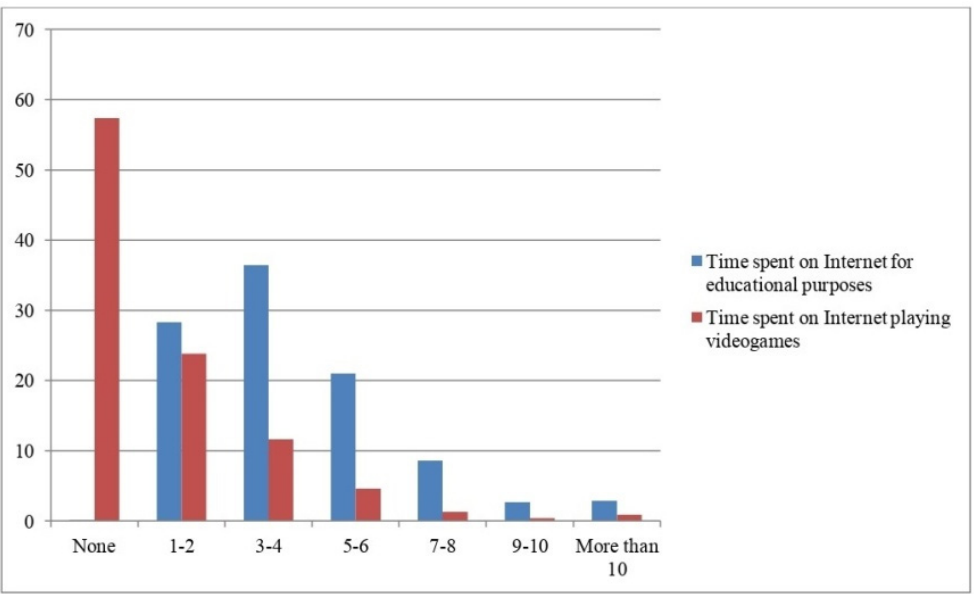

Figure 1. Purpose of hours spent on the Internet.

Table 2. Spearman's rank between the number of hours per day spent playing videogames and gender.

\begin{tabular}{llll}
\hline & & \multicolumn{1}{c}{ 1. Gender } \\
\hline \multirow{3}{*}{ Spearman's rank } & $\begin{array}{l}\text { How many hours } \\
\text { per day? }\end{array}$ & Correlation coefficient & 0.539 \\
\cline { 3 - 3 } & Sign. (two-tailed) & 0.000 \\
\cline { 2 - 3 } & $N$ & 4845 \\
\hline
\end{tabular}

Since there were no significant correlations among the independent variable gender, the use of the Internet for educational purposes, and the number of hours per day, we deduce that more male adolescents play more videogames, while spending more time on the Internet for educational purposes. There were associations between the number of hours per day and the following independent variables: type of educational center (0.239), grade (0.219), and age (0.207). First, we present in Figure 2 the association between the number of hours per day students play videogames and the type of educational center. It can be seen that the students who played more were those from technical institutes. 


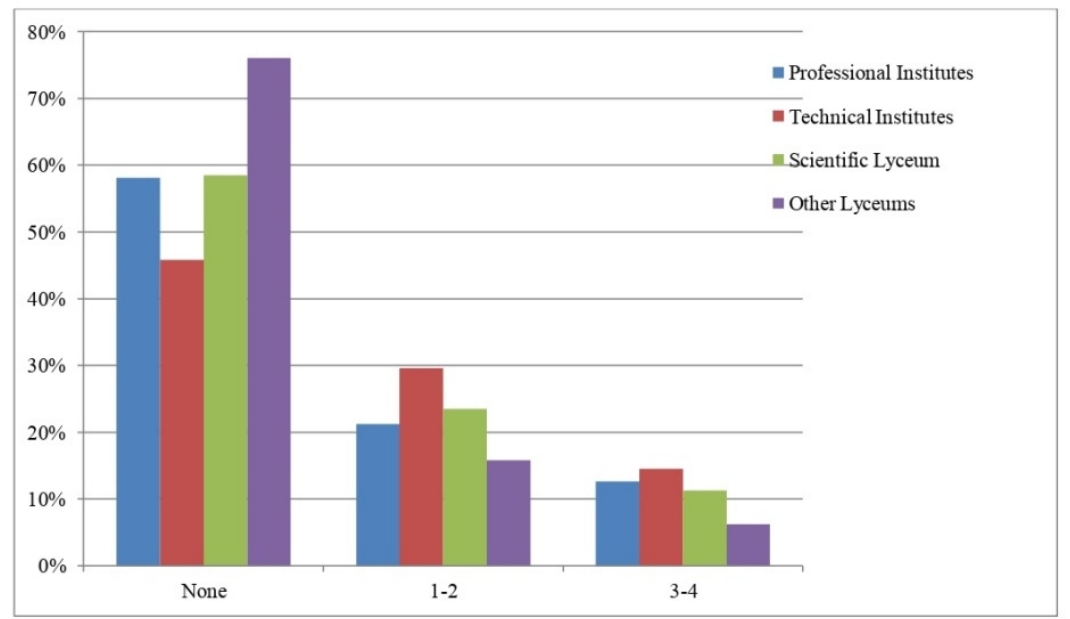

Figure 2. Association between the number of hours per day students play videogames and the type of educational center.

The independent variables of grade and age presented associations suggesting that students within the age range 14-16 years old played more videogames. This information is corroborated in Figures 3 and 4, which demonstrate the relationship between the number of hours per day that students play videogames and the independent variables grade and age. In our study, we were able to verify that there are no correlations with the independent variable academic performance.

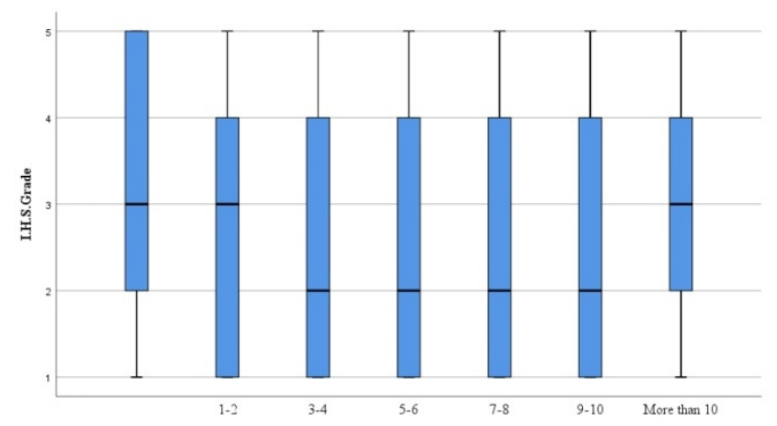

Figure 3. Distribution of the number of hours per day that students play videogames and the independent variable Italian high-school grade.

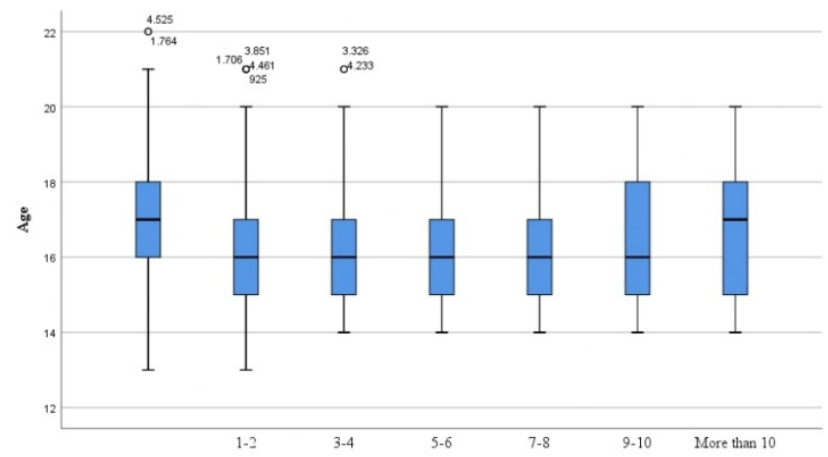

Figure 4. Distribution of the number of hours per day that students play videogames and the independent variable age.

We conclude this first section by stating that high-school students in Italian educational centers use the Internet mainly for educational purposes $(99.7 \%$ versus $43.1 \%$ for videogames). Most of them declared spending 3-4 $\mathrm{h}$ a day for these purposes, while 
typically playing videogames $1-2 \mathrm{~h}$ a day. There were no gender differences in the use of the Internet for educational purposes, but there were gender differences with respect to playing videogames (favoring the male gender). According to the type of school, students from technical institutes played more; according to grade and age, students within the age range 14-16 years old stood out. There was no correlation with academic performance, whether using the Internet for educational purposes or for playing videogames.

\subsection{Category 2. Digital Games or Nondigital Games? Do Games Help in Learning Mathematics?}

In category 2, referring to digital and nondigital games, we presented the students with questions about the use of a videogame to improve their mathematics, and 15.3\% responded positively. We emphasize some significant correlations between the use of videogames in free time and the improvement of mathematics learning. There was a weak correlation (0.269) between playing FIFA or PES2020 and thinking that FIFA or PES2020 serve to improve in mathematics and a moderate correlation (0.312) between playing Fortnite and thinking that Fortnite serves to improve math learning. Another moderate correlation (0.481) was presented between playing Minecraft and thinking of Minecraft as a means to improve math learning. Adolescents who play these games think they can help them improve in math.

To RQ5, referring to the use of a game related to mathematics, $21.1 \%$ replied yes, which was distributed as follows: cards 19.4\%; Sudoku 12\%; Monopoly $8.8 \%$; chess 6.9\%; yes, not specified $52.9 \%$. Although only $21.1 \%$ answered positively to this last question, we identified a correlation (0.249) between the answer "yes, not specified" and the answer "yes, without specifying" regarding the use of a videogame to improve learning in mathematics. Analyzing this correlation more in depth, we found that $61 \%$ of students who played a game related to mathematics considered a videogame to be able to help improve in mathematics. This means that the majority of students who think that games can help in mathematics precisely consider nondigital games; in fact, among the most cited games related to mathematics, we found all nondigital games: cards, Monopoly, Sudoku, chess.

Regarding RQ6 on the use of nondigital games, 73.5\% said yes (sport/outdoor games $20.2 \%$, cards $29.3 \%$, board games $42.9 \%$ ), in contrast to $43.1 \%$ who played videogames in their free time. Thus, we can say that nondigital games are still more practiced.

As we were able to detect in this category, between digital games and nondigital games, students prefer nondigital games. In general, there were not many who believed that videogames can help in mathematics, although some adolescents who played videogames believed otherwise. A larger proportion, on the contrary, considered nondigital games as the most useful in learning mathematics.

\subsection{Category 3. Level of Application of Gamification}

In category 3 , referring to the level of application of gamification, we combined the responses of the students with the responses of the teachers. To RQ7, referring to the proposal of digital/nondigital games in mathematics classes, the students answered negatively (94\% and 95.5\%, respectively). In relation to RQ8, RQ9, and RQ10, referring to the proposal of serious games by teachers and their help in understanding mathematics, the answers were negative in $83 \%$ of cases, whereas $6 \%$ indicated nondigital games (card games, board games, Sudoku, and chess), 5\% indicated digital games without specifying which, 4\% indicated Kahoot, and 2\% indicated competitions. Advancing further with respect to the incorporation of gamification in the classroom, which involves not only the integration of games, but also the methodological changes toward a game scenario, RQ11 and RQ12 received negative answers from the sample in $81 \%$ of cases, whereas $77 \%$ teachers used incentives/prizes/rewards for doing homework well or for doing exercises/problems in class well. Among the affirmative answers to both questions, we found mostly students from professional and technical institutes, and no significant difference was observed by grade. 
The data collected in the sample show us that the level of gamification in secondgrade secondary schools is very low. On the one hand, these data are corroborated by the interviews with the teaching teams. Regarding RQ15, 67\% answered that they did not know what gamification is and, thus, could not express an opinion ("There is little time to test new educational solutions, also considering the many educational outlets in the area" (E-T3: 15); "I do not know but I intend to study it" (E-T9: 39); "I do not know, I do not know it" (E-T2: 10; E-T6: 28; E-T7: 31; E-T10: 44; E-T11: 47; E-T12: 50)). For RQ16, all the people interviewed answered negatively about their receipt of training on gamification, although the research team considered the possibility of "unconscious gamification", with the teachers applying it without knowing it, despite the negative response of the students to the question "During math classes, do the teachers propose digital/nondigital games?" (the data showed a negative response in 94\% and 95.5\% of cases). To RQ17, when we asked the teachers if they knew or proposed any game (digital or not) to their students to help or facilitate the learning of mathematics, $75 \%$ answered positively with guessing games, group competitions, contests, or prizes ("We take games like Sudoku" (E-T1: 6; E-T4: 20; E-T3: 15); "I organize prize contests, riddles, logic games" (E-T2: 10; E-T5: 24; E-T7: 32; E-T8: 35; E-T9: 39; E-T10: 44)). The difference in responses between students and teachers can be justified by the meaning that students give to the word game in the strict sense.

Another difference was found in the question "Do teachers use incentives/prizes/ rewards for doing homework well or for doing exercises/problems in class?", where the students answered negatively in $81 \%$ and $77 \%$ of cases, while the teachers answered affirmatively in $75 \%$ of cases ("Feeling of gratification of a positive comment, sometimes with prizes or incentives" (E-T1: 6; E-T2: 10; E-T3: 15; E-T4: 20; E-T5: 24; E-T8: 36; E-T9: 39; E-T10: 44; E-T11: 48)). Among the data collected in the qualitative study of the teachers, each declared giving different rewards/prizes, not material ones, that the students perhaps did not perceive it as a reward/prize; furthermore, no digital application was shared, according to RQ19, to grant this process.

To investigate the thinking of teaching teams about gamification, RQ20 considered the valuation of the use of the game as a way of accustoming students to always receive rewards for what they do and not make an effort. Accordingly, 67\% of the people interviewed stated that they did not agree with these studies, considering that, with the introduction of the game in didactics, making an effort was more fun ("Those who say that the game does not tend to make an effort, perhaps, they have never played in their life" (E-T2: 10; E-T10: 44; E-T8: 36); "I do not see that students learn by learning, they are already studying for the vote. It is already like that" (E-T3: 15); "You do not always get a reward, or the reward can also just be verbal gratification" (E-T4: 20); "The use of games in educational practices should be a plus, but not the basis" (E-T5: 25; E-T6: 28; E-T7: 32)). Half of them positively evaluated the introduction of the game in didactics, as long as it was not the only educational approach or model.

What was concluded in this category is that the students did not perceive gamification in the classrooms, whether in the sense that the teaching teams in the area of mathematics proposed support games or that they used prizes or rewards for doing their homework well or for doing the exercises/problems in class well. The students also did not claim to know any game, digital or not, that could be done in the hours allocated to the mathematics subject. Teachers declared proposing games to their students that facilitate the learning of mathematics (specifically, guessing games, group competitions, prize contests, riddles, and logic games) and using prizes or rewards (not material). The teaching sample showed that games and prizes/rewards were not understood in the classical/strict sense, and this may have been the reason why students did not perceive them as such. We can affirm that teachers unconsciously put gamification into practice and, if it is not conceived as the only methodology used, the general opinion is the contribution of many benefits. 


\subsection{Category 4. Chess and the Learning of Mathematics}

In order to delve into category 4 on chess, as a serious game, related to learning mathematics, we present different data collected in the study. To RQ13 and RQ14, 68\% of the students answered affirmatively that they can play chess, and, of these, $75 \%$ had at least sufficient marks in the area of mathematics. Moving further in this line of research, we asked whether they knew that chess develops the art of thinking and that seeking "checkmate" helps shape the ability to face and solve mathematical problems. Referring to the first question, $73 \%$ answered positively, whereas, referring to the second question, $40 \%$ answered positively. These percentages did not change much if we considered only the responses of the students who knew the game, i.e., $77.5 \%$ and $43.3 \%$. These data show that knowing the game allows discovering benefits according to RQ14, but does not prevent recognizing them, with a strong association between these last two questions (0.736). Specifically, $94.3 \%$ of those who answered negatively to the first question also answered negatively to the second. These data suggest that the benefits of this game related to facing and solving mathematical problems are not well known to students, which is a pity because, if they did, they could get closer to the area of mathematics through this game.

On the other hand, when asking teachers RQ21, 17\% answered negatively; some said that they did not know the game and that is why they could not evaluate its didactic usefulness ("I know about the usefulness of the chess game, and this is also attested by the fact that, for example, in our library, they bought Chess magazine until last year, but it is a game that I do not know so I cannot judge it as a possible resource" (E-T1: 7); "I can play checkers but not chess" (E-T9: 40)). On the other hand, the majority (67\%) of the teaching teams considered chess a good resource for learning mathematics ("Yes, but not at the secondary school level. I think it is more useful later" (E-T2: 11); "Absolutely yes; all 'strategic' games activate logical skills and inductive thinking, essential in the field of mathematical action" (E-T6: 29; E-T5: 25; E-T8: 36; E-T7: 32); “I think so, but I do not know how to play. I think it can also be a good solution for developing attention and concentration skills. You could think of one hour a week" (E-T10: 45; E-T11: 48; E-T3: 16)).

With regard to chess, we can affirm that the students who played recognized its usefulness to enhance the art of thinking, but they did not recognize its usefulness in shaping the ability to face and solve mathematical problems. Furthermore, $75 \%$ of students who knew how to play chess had at least sufficient performance in the area of mathematics. From the teachers' point of view, this game could have advantages, not only in mathematics, but more generally; it could influence other transversal skills, such as attention and concentration, as well as activate/improve logic skills and inductive thinking.

\section{Discussion}

As shown in several studies $[8,13,14]$, if well used and introduced, gamification and serious games can change the methodology, increase the motivation to learn mathematics, and improve the progress made by students.

Italian adolescent students spent more time on the Internet for educational rather than recreational purposes [H1]. This use of the Internet for educational purposes did not depend on the independent variables gender, age, type of school, grade, and academic performance; indiscriminately, students used the Internet for educational purposes [H2]. Using the Internet for videogames depended on the independent variables gender, age, type of school, and grade [H3], but not academic performance. Male students played videogames, especially students of technical institutes and those in the age range of 14-16. The data show that the games most used by high-school students were nondigital games [H4]. Despite the fact that Italian adolescents think that games cannot be helpful for learning mathematics [H5], there were strong positive correlations suggesting the benefits of videogames toward learning mathematics as perceived by the players, specifically with FIFA or PES2020, Fortnite, and Minecraft; the students who thought that games can be helpful for learning mathematics cited in particular cards, Monopoly, Sudoku, and chess. 
Despite the teachers not having received training in the field of gamification, we observed in high schools an "unconscious gamification", whereby the teachers did not know what gamification is or received training on it, but declared proposing tasks to their students that help or facilitate the learning of mathematics such as group competitions, prize contests, riddles, logic games, and the use of prizes or rewards [H6]. Lastly, regarding the consideration of chess as a serious game [H7], we observed that students did not recognize the benefits of chess for learning mathematics, although the teaching staff believed in the use of chess as a serious game [H8].

Observing our results, a change is necessary in the didactic processes that underpin the learning of mathematics in high schools in Italy. A positive aspect is that, unconsciously, gamification is applied; however, on the other hand, we observed that none of the teaching teams received any training, and, despite recognizing the mathematical benefits of chess, this game was not used as a serious game in the classroom. Our study confirms that, for Italian secondary-school teachers, the gamification technique is not the only educational approach or model, but it deserves more attention for the benefits it brings, especially for a subject that scares students and demands greater motivation. To apply gamification or introduce serious games in the classroom, teachers, thanks to their training, have to become learning influencers [39], as well as for a source of ideas and proposals; gamification requires interactive relationships to make students the protagonists of educational action, and the role of teachers is fundamental. These teachers need to build a network, not a route, and the students should become the "architects of routes".

The path toward this new direction will not be short or easy; however, our study seeks to contribute our "grain of sand" to the development of broader investigations. Gamification not only improves learning, but also improves all those behaviors for which it is considered necessary to intervene [40]. Regarding the perception of chess as a serious game for mathematics, we found a significant result ( $75 \%$ of students who knew how to play chess had at least sufficient performance in the area of mathematics); thus, considering benefits of this game as analyzed in previous studies [18-23], it is possible to think of a future investigation with a design including pre-test and post-test and a control group and a treatment group in secondary school. It is essential to continue researching the role of gamification and serious games in the development of learning within the area of mathematics in order to improve the quality of teaching and give this discipline the motivation it deserves.

Author Contributions: Investigation, V.M. and J.G.-Q.; Writing—review and editing, V.M., J.G.-Q. and E.B. All authors have read and agreed to the published version of the manuscript.

Funding: This research received no external funding.

Institutional Review Board Statement: Not applicable.

Informed Consent Statement: Informed consent was obtained from all subjects involved in the study.

Data Availability Statement: Not applicable.

Conflicts of Interest: The authors declare no conflict of interest. The funders had no role in the design of the study; in the collection, analyses, or interpretation of data; in the writing of the manuscript, or in the decision to publish the results.

\section{References}

1. Grande, M.; Abella, V. Los juegos de rol en el aula. Teoría Educ. Educ. Cult. Soc. Inf. 2010, 11, 56-84. [CrossRef]

2. Kapp, K.M. The Gamification of Learning and Instruction Fieldbook: Ideas into Practice; John Wiley \& Sons: Hoboken, NJ, USA, 2013.

3. Banfield, J.; Wilkerson, B. Increasing student intrinsic motivation and self-efficacy through gamification pedagogy. Contemp. Issues Educ. Res. (CIER) 2014, 7, 291-298. [CrossRef]

4. Díaz-Delgado, N. Gamificar y transformar la escuela. Rev. Mediterránea Comun./Mediterr. J. Commun. 2018, 9, 61-73. [CrossRef]

5. Gil-Quintana, J.; Ortega, R.M. Gamificación. apostando por una comunicación interactiva y un modelo participativo en educación. Commun. Pap. 2018, 7, 9-22. [CrossRef] 
6. Giménez, P. Hacia una propuesta pedagógica de los juegos de rol. Primeras Noticias. Rev. Lit. 2003, 195, 81-84.

7. Denny, P.; McDonald, F.; Empson, R.; Kelly, P.; Petersen, A. Empirical support for a causal relationship between gamification and learning outcomes. In Proceedings of the 2018 CHI Conference on Human Factors in Computing Systems, Montréal, QC, Canada, 21-26 April 2018.

8. Xi, N.; Hamari, J. Does gamification satisfy needs? A study on the relationship between gamification features and intrinsic need satisfaction. Int. J. Inf. Manag. 2019, 46, 210-221. [CrossRef]

9. Del Cerro, G.M. Aprender jugando, resolviendo: Diseñando experiencias positivas de aprendizaje. In Proceedings of the XII International Conference on University Innovation, Villaviciosa de Odón, Spain, 20-21 July 2015; Available online: http: / / hdl.handle.net/11268/4334 (accessed on 29 March 2021).

10. Gil-Quintana, J.; Prieto, E. Juego y gamificación: Innovación educativa en una sociedad en continuo cambio. Rev. Ens. Pedagógicos 2019, 14, 69. [CrossRef]

11. Karageorgiou, Z.; Mavrommati, E.; Fotaris, P. Escape room design as a game-based learning process for steam education. In Proceedings of the 13th European Conference on Games Based Learning, Odense, Denmark, 3-4 October 2019; pp. 378-385. [CrossRef]

12. Montessori, M. Il Metodo della Pedagogia Scientifica Applicato All'Educazione Infantile Nelle Case Dei Bambini; Loescher: Turin, Italy, 1913.

13. Sini, C. Il Gioco del Silenzio; nu se Lasa Nicio Data; Mimesis: Milan, Italy, 2013.

14. Anastasiadis, T.; Lampropoulos, G.; Siakas, K. Digital game-based learning and serious games in education. Int. J. Adv. Sci. Res. Eng. (Ijasre) 2018, 4, 139-144. [CrossRef]

15. Trinchero, R.; Sala, G. Chess training and mathematical problem-solving: The role of teaching heuristics in transfer of learning Eurasia J. Math. Sci. Technol. Educ. 2016, 12, 655-668. [CrossRef]

16. Martini, B. Il Sistema Della Formazione Ai Saperi. Soggetti, Oggetti, Istituzioni; Tecnodid: Naples, Italy, 2012.

17. Baldacci, M. Prospettive per la Scuola D'infanzia. Dalla Montessori Al XXI Secolo; Carocci: Rome, Italy, 2015.

18. Sala, G.; Gobet, F. Do the benefits of chess instruction transfer to academic and cognitive skills? A meta-analysis. Educ. Res. Rev. 2016, 18, 46-57. [CrossRef]

19. Rosholm, M.; Mikkelsen, M.B.; Gumede, K. Your move: The effect of chess on mathematics test scores. PLoS ONE 2017, 12, e0177257. [CrossRef]

20. Işıkgöz, E. Analysis on math success of secondary school students playing and not playing chess (Sakarya province sample). J. Hum. Sci. 2016, 13, 1689-1699. [CrossRef]

21. Bocciolesi, E. Pedagogía de la Literacidad. Reflexiones Hacia la Construcción de una Competencia Compleja; Editorial Universitaria: Guadalajara, Mexico, 2018.

22. López, V.; Couso, D.; Simarro, C. Educación STEM en y para el mundo digital. Rev. Educ. Distancia 2020, 20, 31-34. [CrossRef]

23. Invalsi. Rapporto Prove Invalsi 2019. Rapporto Nazionale. Available online: https://invalsi-areaprove.cineca.it/docs/2019 /Rapporto_prove_INVALSI_2019.pdf (accessed on 29 March 2021).

24. Di Martino, P.; Zan, R. Me and maths: Towards a definition of attitude grounded on students narratives. J. Math. Teach. Educ. 2010, 13, 27-48. [CrossRef]

25. Lucio, D.M. La Tecnología y Su Afección en la Salud Visual en Personas de 20-30 Años, de la Ciudadela Galo Cedeño. Bachelor's Thesis, Universidad Técnica de Babahoyo, Puebloviejo-Los Ríos, Equador, 2019.

26. Arrivillaga, C.; Rey, L.; Pacheco, N.E. Uso Problemático del Smartphone y Ajuste Psicológico en Adolescentes: El Papel Clave de la Inteligencia Emocional. Know Share Psychol. 2020, 1, 147-158. [CrossRef]

27. Fiderio, T.; Gambino, G.; Germanà, F.M.; Morello, M.; Ruvolo, L.; Scuderi, G. Relazioni Umane e Tecnologie Dispositive; Accademia Higorà: Palermo, Italy, 2020.

28. Stake, R.E. Qualitative case studies. In The Sage Handbook of Qualitative Research; Denzin, N.K., Lincoln, Y.S., Eds.; SAGE Publications: Thousand Oaks, CA, USA, 2005; pp. 443-466.

29. Rule, P.; Mitchell, J. A Necessary Dialogue: Theory in Case Study Research. Int. J. Qual. Methods 2015, 14, 1-11. [CrossRef]

30. Stake, R.E. Investigación con Estudio de Casos; Ediciones Morata: Madrid, Spain, 2007.

31. Barton, J.; Stephens, J.; Haslett, T. Action Research: Its Foundations in Open Systems Thinking and Relationship to the Scientific Method. Syst. Pract. Action Res. 2009, 22, 475-488. [CrossRef]

32. Igartua, J.J.; Humanes, M.L. Teoría e Investigación en Comunicación Social; Síntesis: Madrid, Spain, 2009.

33. Gibbs, G. El Análisis de Datos Cualitativos en Investigación Cualitativa; Ediciones Morata: Madrid, Spain, 2012.

34. Valles, M. Técnicas Cualitativas de Investigación Social; Síntesis: Madrid, Spain, 2000.

35. Iñiguez, L. Análisis del Discurso: Manual Para las Ciencias Sociales; UOC: Barcelona, Spain, 2006.

36. Van Dijk, T.A. Ideología y análisis del discurso. Utopía Prax. Latinoam. 2005, 10, 9-36.

37. Johnson, R.; Onwuegbuzie, A.J. Mixed Methods Research: A Research Paradigm Whose Time Has Come. Educ. Res. 2004, 33, 14-26. [CrossRef]

38. Callejo, J.; Viedma, A. Proyectos y Estrategias de Investigación Social: La Perspectiva de Intervención; McGraw-Hill: New York, NY, USA, 2006. 
39. Gil-Quintana, J.; Malvasi, V.; Castillo-Abdul, B.; Romero-Rodríguez, L.M. Learning Leaders: Teachers or Youtubers? Participatory Culture and STEM Competencies in Italian Secondary School Students. Sustainability 2020, 12, 7466. [CrossRef]

40. Valero-García, M. Gamificación (Incluye Propuestas). Available online: http://personals.ac.upc.edu/miguel/materiales/ docencia/articulos/Gamificacion.pdf (accessed on 10 April 2021). 